\title{
Detection of Extraocular Lesions in A Patient with Bilateral Retinoblastoma Using ${ }^{18}$ F-FDG PET/CT
}

\author{
Luis Guillermo Roncallo Kelsey, Caio Faber Vayego, Cláudio Yoiti Inafuku, Euclides Timóteo da Rocha, \\ Marcelo José dos Santos and Wilson Eduardo Furlan Matos Alves* \\ Nuclear Medicine and Molecular Imaging Department, Barretos Cancer Hospital, Brazil \\ *Corresponding author: Wilson Eduardo Furlan Matos Alves, Nuclear Medicine and Molecular Imaging Department, \\ Barretos Cancer Hospital, Brazil
}

\section{ARTICLE INFO}

Received: 幽 April 10, 2019

Published: 閊 April 18, 2019

Citation: Luis G R K, Caio F V, Cláudio Y I, Euclides T d R, Wilson E F M A. Detection of Extraocular Lesions in A Patient with Bilateral Retinoblastoma Using ${ }^{18} \mathrm{~F}$-FDG PET/CT.

Biomed J Sci \& Tech Res 17(2)-2019. BJSTR. MS.ID.002968.

\section{ABSTRACT}

Retinoblastoma is the most common ocular malignancy in children with a high mortality rate in metastatic disease, even under chemotherapy. The diagnosis is done through clinical evaluation and biopsy. Imaging tests such as computed tomography (CT), bone scan and magnetic resonance imaging (MRI) play an important role in the staging and detection of distant metastases. The 18F-FDG PET/CT may complement the evaluation of metastatic disease in retinoblastoma.

Keywords: Retinoblastoma; 18F-FDG PET/CT; Distant Metastases

Abbreviations: CT: Computed Tomography; MRI: Magnetic Resonance Imaging; PET/CT: Positron Emission Tomography; 18F-FDG: 18F-Fluorodeoxyglucose; IRSS: International Retinoblastoma Staging System

\section{Introduction}

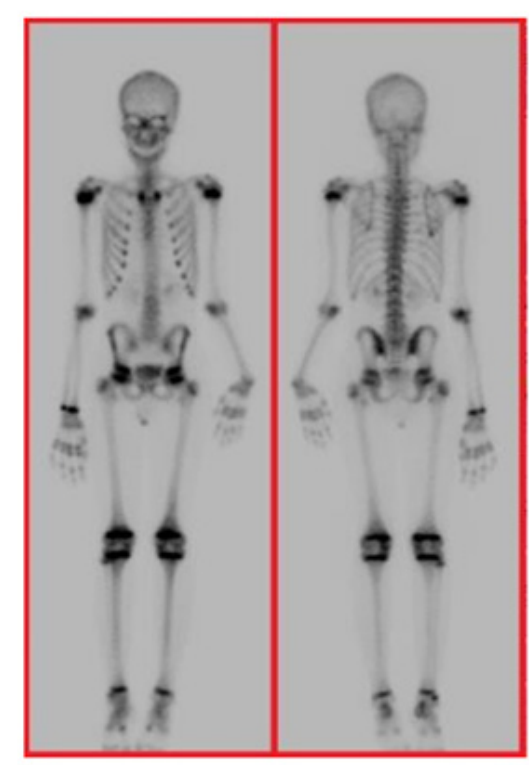

Figure 1: Bone scintigraphy with ${ }^{99 \mathrm{~m} T c-}$ MDP without evidence of osteoblastic metastatic lesions. 


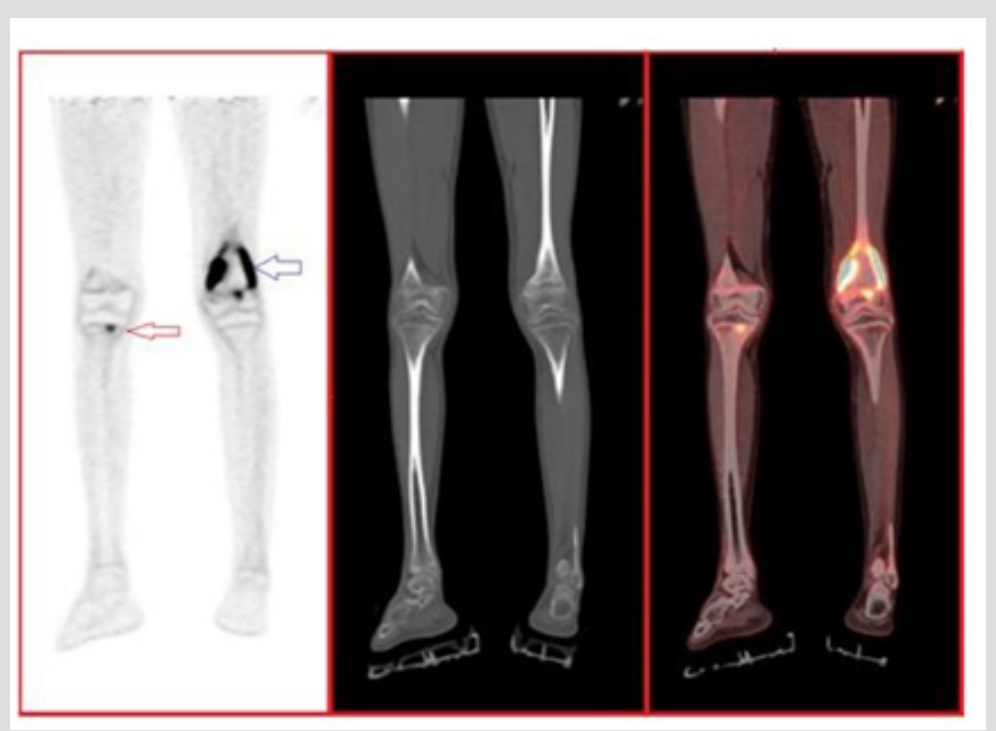

Figure 2: ${ }^{18} \mathrm{~F}-\mathrm{FDG}$ PET/CT image in the coronal sections showing the bone lesions, one in the left femur (blue arrow) and the other in the proximal epiphyseal plate of the right tibia (red arrow).
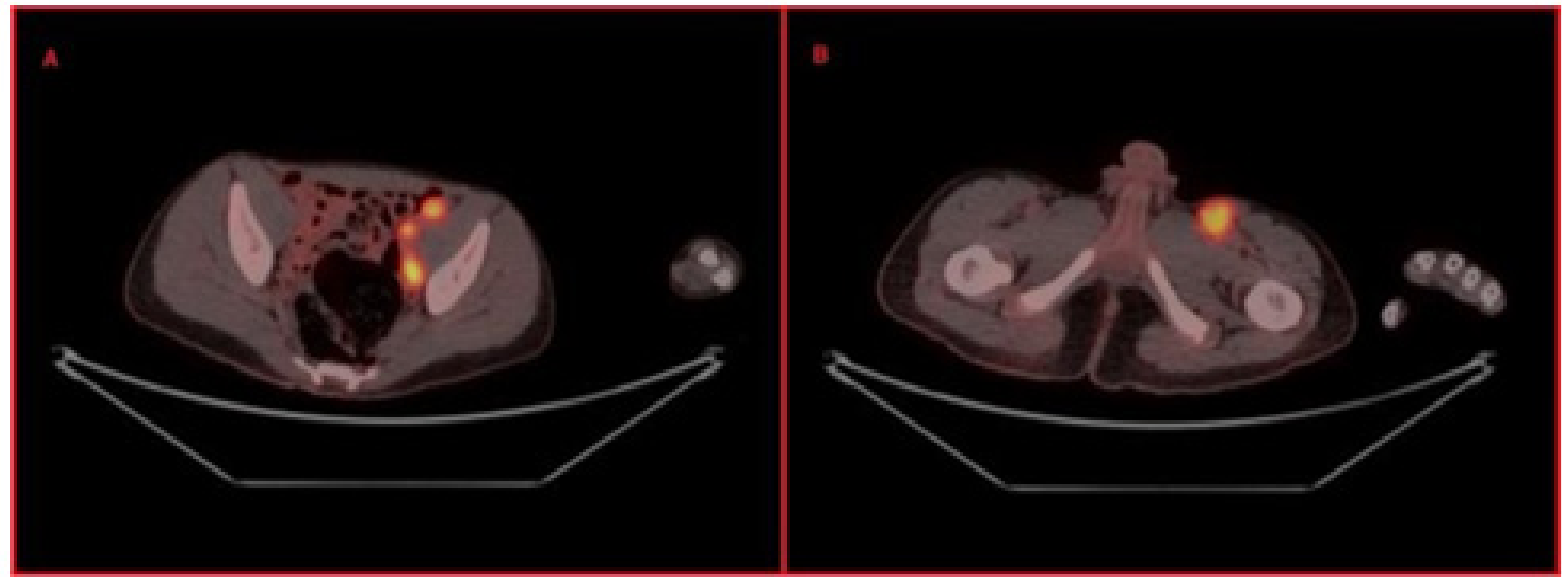

Figure 3: ${ }^{18} \mathrm{~F}-\mathrm{FDG}$ PET/CT image in the axial sections presenting hypermetabolic lymph node enlargement in the left external iliac (A) and left inguinal (B) chains

A 10-year-old male patient was diagnosed with bilateral retinoblastoma at 10 months of age. Over time, enucleation of the left eye and external radiation therapy on the right eye were performed in addition to chemotherapy. In 2014, he presented his first bone relapse in the left radius and, in 2016, the second in the left femur. Surgery on left radius and radiotherapy on left femur were done in addition to chemotherapy in both times. In 2017, even with bone scintigraphy showing no osteoblastic lesions (Figure 1), the patient was submitted to ${ }^{18} \mathrm{~F}$-FDG-PET/CT due to persistence of left knee pain, with no sign of local inflammation. An intramedullary lesion was detected in the distal metaphyseal region of the left femur and in soft tissue around (SUVmax = 11.8) and another sclerotic, in the medial region of the proximal epiphyseal plate of the right tibia (SUVmax $=4.0$ ) (Figure 2), and lymph node enlargement in external iliac, obturator, inguinal and popliteal chains on the left (SUVmax =
8.3) (Figure 3). The left femur lesion was viewed also by MRI and biopsy confirmed it as secondary to retinoblastoma.

\section{Discussion}

Retinoblastoma is the most common ocular malignancy and its incidence is 1 in 15,000-20,000 live births [1]. In about $40 \%$ of the cases, retinoblastoma is bilateral and all of them are hereditary associated to mutations on gene RB1, localized in chromosome 13q1.4 [1]. Examination of ocular fundus determines the diagnosis and ultrasound, magnetic resonance imaging (MRI) and computed tomography (CT) complement the assessment by differentiating it from other ocular diseases like Coats disease [1,2]. Besides ocular involvement, soft tissue of the orbit, cervical lymph nodes, bone, bone marrow and central nervous system metastases may occur and generally, they are accompanied by high mortality rate mainly at 
in developing countries where the diagnosis is late [1]. Currently, 18F-FDG PET/CT has been showed an interesting tool to available retin o b la s t o m a. Radhakrishnan et al showed prognostic value of 18F-FDG PET/CT optic nerve uptake at baseline and response after neoadjuvant chemotherapy in International Retinoblastoma Staging System (IRSS) stage III patient [3]. Moreover, 18F-FDG PET/ CT have higher sensitivity to detect bone metastases did not see at bone scan [3], as observed in our case. Other possibility is to evaluate soft tissue metastases, mainly whole-body MRI has not been available. Based in our case and in its value prognostic [3], new studies using 18F-FDG PET/CT for staging of advanced retinoblastoma could showed its real significance.

ISSN: 2574-1241

DOI: 10.26717/BJSTR.2019.17.002968

Wilson Eduardo Furlan Matos Alves. Biomed J Sci \& Tech Res

This work is licensed under Creative Commons Attribution 4.0 License

Submission Link: https://biomedres.us/submit-manuscript.php

\section{References}

1. Aerts I, Lumbroso Le Rouic L, Gauthier Villars M, Brisse H, Doz F, et al. (2006) Retinoblastoma. Orphanet journal of rare diseases 1(1): 31.

2. De Graaf P, Göricke S, Rodjan F, Galluzzi P, Maeder P, et al. (2012) Guidelines for imaging retinoblastoma: imaging principles and MRI standardization. Pediatric radiology 42(1): 2-14.

3. Radhakrishnan V, Kumar R, Malhotra A, Bakhshi S (2012) Role of PET/ CT in staging and evaluation of treatment response after 3 cycles of chemotherapy in locally advanced retinoblastoma: a prospective study. Journal of Nuclear Medicine 53(2): 191-198.

$\begin{array}{ll}\text { BIOMEDICAL } & \text { Assets of Publishing with us } \\ \text { RESEARCHES } & \text { - Global archiving of articles } \\ & \text { - Immediate, unrestricted online access } \\ & \text { - Rigorous Peer Review Process } \\ \end{array}$

